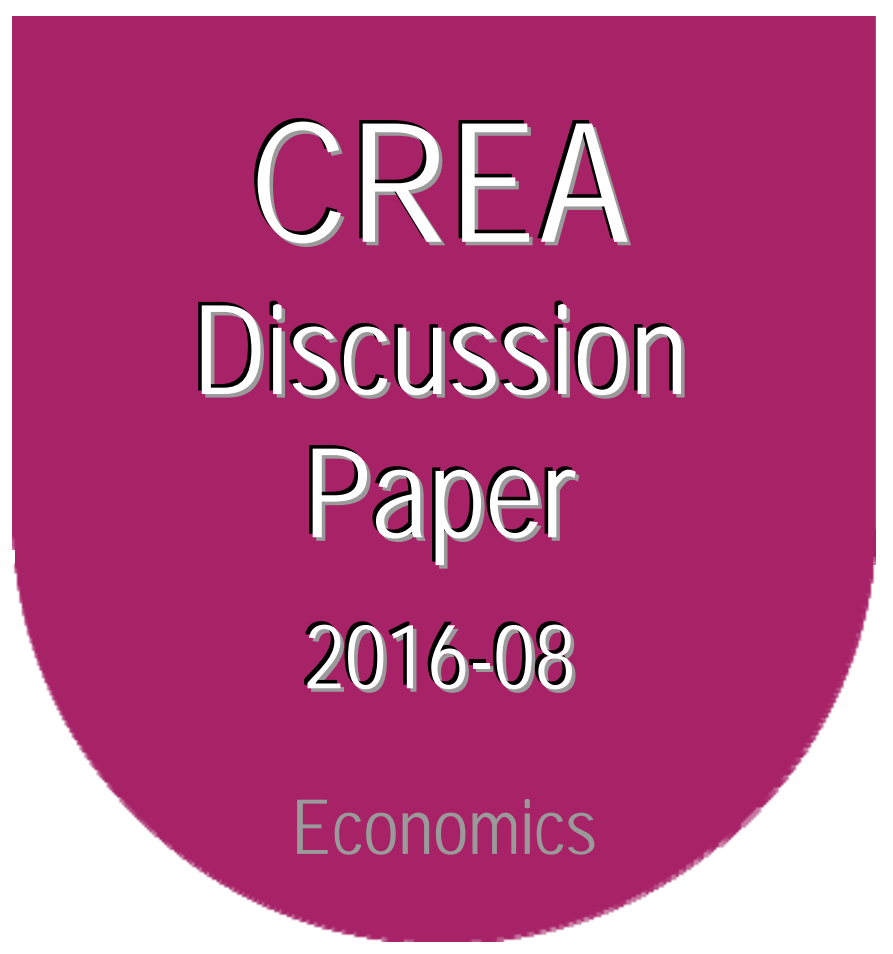

Centre for Research in Economics and Management University of Luxembourg

\title{
Equilibrium and first-best city with endogenous exposure to local air pollution from traffic
}

available online : http://wwwfr.uni.Iu/recherche/fdef/crea/publications2/discussion_papers

Mirjam Schindler, IPSE, Université du Luxembourg Geoffrey Caruso, IPSE, Université du Luxembourg Pierre M. Picard, CREA, Université du Luxembourg

August, 2016

For editorial correspondence, please contact: crea@uni.lu University of Luxembourg Faculty of Law, Economics and Finance 162A, avenue de la Faïencerie L-1511 Luxembourg 


\title{
Equilibrium and first-best city with endogenous exposure to local air pollution from traffic
}

\author{
Mirjam Schindler ${ }^{\mathrm{a}, *}$, Geoffrey Caruso $^{\mathrm{a}}$, Pierre Picard ${ }^{\mathrm{b}}$ \\ ${ }^{a}$ Institute of Geography and Spatial Planning, University of Luxembourg \\ ${ }^{b}$ CREA, University of Luxembourg; CORE, Université Catholique de Louvain
}

\begin{abstract}
Exposure to urban traffic-induced air pollution is a major health concern of cities. This paper analyzes the urban structure when localized pollution exposure arises from commuting traffic and investigates the feedback effect of endogenous pollution on residential choices. The presence of stronger traffic-induced air pollution exposure reduces the geographical extent and the population of cities. Land rents fall with distance from the city center while population densities may be non-monotonic. Cleaner vehicle technologies reduce pollution exposure everywhere, increase population and density everywhere and do not affect the spatial extent of the city. The paper compares the urban equilibrium with the first-best. The first-best structure is a less expanded city with higher densities at the center and lower densities at the fringe.
\end{abstract}

Keywords: residential choice, traffic-induced air pollution, localized pollution exposure, urban structure

\section{Introduction}

Despite technological improvements and reduction in air pollution emissions over the last years (WHO, 2014), air pollution remains a major concern.

${ }^{*}$ Corresponding author. Tel.: +352 466644 9239. Institute of Geography and Spatial Planning, University of Luxembourg, Maison des Sciences Humaines 11, Porte des Sciences, 4366 Esch-Belval, Luxembourg

Email addresses: mirjam.schindler@uni.lu (Mirjam Schindler), geoffrey.caruso@uni.lu (Geoffrey Caruso), pierre.picard@uni.lu (Pierre Picard) 
More than 400,000 Europeans still die prematurely each year because of air pollution (EEA, 2014). It is a particular concern for urban areas where population is highly concentrated and traffic is the major source of primary pollutants (EEA, 2014). In China, $87 \%$ of major cities were recently declared to exceed the guidelines set by the World Health Organization in terms of air pollution concentrations (Zhang and Cao, 2015). Pollution from urban traffic is acknowledged to cause harmful effects not only on the environment but also on human health. Besides their concerns for accessibility and housing space, residents are preoccupied by the health impact of air pollution in their close neighborhood (Chay and Greenstone, 2005; WHO, 2014) and display higher willingness to pay to live in less polluted neighborhoods (e.g. Smith and Huang, 1995; Bickerstaff and Walker, 2001; Lera-López et al., 2012).

As residents have incentives to relocate to less polluted urban areas, they may make longer commuting trips to their workplaces, thereby generating additional pollution and exposing other residents further. As a result, the spatial distribution of both residents and urban pollution is strongly intertwined. This endogeneity between the choice of residence and pollution patterns calls for a dedicated study of the spread of pollution and residences. While urban compaction policies might address environmental concerns linked to total urban emissions, more dispersed urban development might well be beneficial in terms of reducing the impact of localized pollutants, improving local households' well-being and health (e.g. Borrego et al., 2006; Manins et al., 1998; Martins, 2012; De Ridder et al., 2008; Marshall et al., 2005; Schindler and Caruso, 2014). In order to design appropriate urban environmental policies, one requires a detailed understanding of how households' choices and urban structures interact and impact emission generation and health. This is the purpose of this paper.

We extend the standard monocentric city model (Alonso, 1964) with an endogenous local pollution externality that arises from the traffic passing at each location. Our central issue is the endogenous link between pollution exposure and residential choices. We investigate the effects of localized traffic pollution. Allowing for an analytical solution, the model offers a detailed investigation of the feedback effect of endogenous local pollution externalities on residential choices. We show that the stronger the aversion and exposure to traffic-induced pollution are, the smaller are the geographical extent and the population of the city. Households tend to reside further away from the CBD to reduce their exposure to pollution, which creates a tension on the land market near the city border. Land rents fall with distance from the 
CBD while population densities may be non-monotonic. We also show that cleaner vehicle technologies reduce pollution exposure everywhere, increase the city population and its density everywhere and do not affect the spatial extent of the city. They induce higher and steeper land rents everywhere and non-monotonic population density profiles are possible for a smaller set of parameters. Compared to previous urban economics literature with aggregate city-wide pollution (e.g. Verhoef and Nijkamp, 2003), we show that lower local traffic-induced air pollution differs from a lower city-wide pollution in terms of its effects on the city extent, the population density and the land rent gradient. Finally, the socially optimal city structure is a less expanded city with smaller population and may also hold non-monotonic population densities. The first-best has higher densities at the center and lower densities at the fringe. The first-best can be decentralized through a localized lump-sum tax.

In contrast to this paper, the urban economic literature mostly focuses on urban air pollution generated by exogenous sources (e.g. Henderson, 1977; Arnott et al., 2008; Rauscher, 2009; Kyriakopoulou and Xepapadeas, 2013) or by endogenous industrial sources (Regnier and Legras, 2014). A few urban economic contributions consider traffic-induced pollution (e.g. Fisch, 1975; Robson, 1976; Proost and Dender, 1998; Van Marrewijk, 2005; Marshall et al., 2005; Lange and Quaas, 2007; Boadway et al., 2011; Gaigné et al., 2012). Fisch (1975) introduces traffic-induced pollution as a cost (for analytical tractability) in a close city and discusses numerical simulations about pollution taxes. Robson (1976) introduces traffic-induced pollution as a disutility also in a closed city model. In contrast to our paper, however, he does not introduce the standard trade-off between residential and commuting choices (again for analytical tractability). McConnell and Straszheim (1982) discuss automobile pollution and congestion and provide numerical assessments of pricing and emission policies. Close to this paper, Verhoef and Nijkamp (2003) discuss numerical simulations of an urban model where residents are homogeneously harmed by the 'total pollution' generated by commuters. However, pollution externalities are spatially differentiated: while some pollutants like ozone are undoubtedly of a regional nature, primary emissions like $C O, P M_{2.5}$ and $P M_{10}$ vary locally (e.g. Colvile et al., 2001; Jerrett et al., 2005; Kingham et al., 2000). To our knowledge, the impact of local pollution exposure from urban commuting has not been studied in an open city framework. This paper, thus, departs from previous literature and provides a general framework to study technological and societal impacts 
on urban and pollution patterns. It offers a rejoinder to results by Robson (1976) and Verhoef and Nijkamp (2003) but takes on a per-distance pollution perspective. Urban properties are derived, comparative statics are performed and the optimal urban policy is analyzed.

The remainder of the paper is organized as follows: Section 2 presents the model and the competitive land market equilibrium with housing choice and traffic-induced air pollution. Conditions for the existence of equilibrium and equilibrium properties are analyzed. Section 3 presents comparative statics on the exogenous model parameters. In Section 4, the first-best policy allocation and optimal city structure are presented and compared to the equilibrium ones. Section 5 discusses and concludes. Appendices A and B contain the proofs.

\section{Urban equilibrium}

In the tradition of Alonso (1964), we use a linear monocentric urban model with a spaceless CBD at distance $r=0$, identical households and absentee landlords. The city is open and households migrate into the city as long as they gain a higher utility than the utility obtained in the rest of the world, $\bar{u}$. Each household is endowed with a Cobb-Douglas utility function ${ }^{1}$ that includes the exposure to the local pollution $P(r)$ induced by the commuting traffic passing through the location at distance $r$ to the $\mathrm{CBD}$, in addition to a general basket of goods $Z(r)$ and housing space $H(r)$

$$
U=\kappa H(r)^{\alpha} Z(r)^{1-\alpha} P(r)^{-\beta}
$$

where $\alpha$ and $(1-\alpha)$ represent the preference for each good respectively $(0<\alpha<1)$, and $\beta$ the aversion to pollution exposure $(0<\beta<1)$. For convenience, we use $\kappa \equiv(1-\alpha)^{\alpha-1} \alpha^{-\alpha}$ as a simplification constant.

Besides the housing and composite consumptions, households spend their income $Y$ on a commuting cost $t r$, which is linear with distance from the CBD and there is no congestion. They maximize utility subject to the following budget constraint

$$
H(r) R(r)+Z(r)+t r \leq Y
$$

where $R(r)$ is the rent per acre at location $r$.

\footnotetext{
${ }^{1}$ The Cobb-Douglas is also chosen by Fisch (1975) and Robson (1976).
} 
Each household residing at location $r$ undergoes a negative externality from being exposed to air pollutants generated by commuters who live at further distances from the CBD, up to the urban boundary $r_{f}$, and pass by $r$ on their trip to work. We assume that there is one commuter per household as in previous models (e.g. Anas and Xu, 1999). Exposure to local pollution ${ }^{2}$ $P(r)$ is increasing with the traffic volume passing by $r$

$$
P(r)=1+a+b \int_{r}^{r_{f}} n(r) \mathrm{d} r
$$

The parameters $a>0$ and $b>0$ measure the impacts of the regional and traffic-induced pollution in the city. Regional pollution originates from sources other than commuting traffic and is assumed to be the same over the city (Fowler et al., 2013). Traffic-induced pollution depends on the traffic volume $\int_{r}^{r_{f}} n(r) d r$ and the vehicle technology $b$ which is expressed in terms of pollution emission per vehicle and unit of traveled distance. ${ }^{3}$ Since most industrial or agricultural pollutants are largely independent from population growth (Cramer, 2002), $a$ is exogenous in our model, i.e. not related to the total city population. In the absence of pollution $(a=b=0)$, the pollution profile $P(r)$ is equal to one and does not affect the utility level.

In equilibrium, all households get the same reservation utility level $\bar{u}$, no matter their residential location since they are identical and migration is free. The equilibrium is defined by the functions $Z(r), H(r), P(r)$ and $R(r)$ and the scalar $r_{f}$ that satisfy the pollution exposure property (2.3) and the land allocation property $R(r)=\max \left\{\Psi(r), R_{A}\right\}$, where $\Psi(r)$ is the unit land bid rent given by

$$
\Psi(r)=\max _{Z(r), H(r)} \frac{Y-t r-Z(r)}{H(r)} \text { s.t. } U(Z(r), H(r), P(r)) \geq \bar{u}
$$

\footnotetext{
${ }^{2}$ The functional form for the externality follows from Robson (1976). It does not include a spatial diffusion component (e.g. Kyriakopoulou and Xepapadeas (2013)) in order to analyze only direct local effects of location choice and because our aim is an analytical model solution and analysis.

${ }^{3}$ Distance effects on engine temperature and emissions have been considered in simulations by Schindler and Caruso (2014) but would add terms within the integral of the pollution equation here, which is an unnecessary complication at this stage.
} 
The unit land bid rent expresses the maximum land rent that the household is willing to pay given its outside utility $\bar{u}$ and income $Y$. Households take the pollution profile as given.

In the following, we drop the reference to $r$ for $Z, H, P$ and $R$ for conciseness whenever possible.

Consumption. The household's demand function for housing $H$ and composite good $Z$ are derived from the maximization problem (2.4). As noted in Fujita and Thisse (2002), households have no incentives to get a surplus over their utility $\bar{u}$ so that the constraint (2.4) binds. Defining $\widehat{H}(Z, \bar{u})$ as the unique solution of $U(Z, H, P)=\bar{u}$, we can find the consumption of the composite good $Z$ that maximizes the bid rent $\widehat{\Psi}(r, Z) \equiv(Y-t r-Z) / \widehat{H}(Z, \bar{u})$. Equating $d \widehat{\Psi}(r, Z) / d Z$ to zero we find the equilibrium demand functions for the composite good $Z$ and then housing $H$ as

$$
\begin{aligned}
& Z=(1-\alpha)(Y-t r) \\
& H=\alpha \bar{u}^{1 / \alpha} P^{\beta / \alpha}(Y-r t)^{-(1-\alpha) / \alpha}
\end{aligned}
$$

One can show that $(\mathrm{d} / \mathrm{d} Z) \widehat{\Psi}(r, Z)$ changes once from positive to negative so that this solution yields a maximum. Housing consumption rises with pollution exposure. To keep households in more polluted locations, landlords must compensate them with lower land rent and larger residences. For positive consumption, we assume $Y-t r_{f}>0$ in the sequel.

Spatial distribution of pollution exposure. The spatial distribution of pollution exposure is derived from the population density distribution $n(r)$, which itself is derived from the equilibrium housing consumption after normalizing available land everywhere to unity: $n(r)=1 / H(r)$. Since $P$ is differentiable we can replace definition (2.3) by

$$
\dot{P}=-b / H \quad \text { and } \quad P\left(r_{f}\right)=1+a
$$

where the dot superscript refers to the derivative with respect to $r, \dot{P}=$ $\mathrm{d} P / \mathrm{d} r$. The above identity reflects the two-way dependence of housing consumption and pollution exposure distribution within the city. Since $H>0$, local pollution exposure is a decreasing function of distance from the CBD. 
Using the above expression of $H$, we get the following differential equation:

$$
\dot{P} P^{\beta / \alpha}=-b \alpha^{-1} \bar{u}^{-1 / \alpha}(Y-t r)^{(1-\alpha) / \alpha}
$$

where $P P^{\beta / \alpha}$ is equivalent to $(\alpha /(\alpha+\beta))(d / d r) P^{(\alpha+\beta) / \alpha}$. Then, assuming $r \in\left[0, r_{f}\right]$ and $r_{f}<Y / t$, this expression integrates to

$$
P=P_{0}\left[a_{0}+\frac{t}{\alpha} \int_{r}^{r_{f}}(Y-t s)^{(1-\alpha) / \alpha} \mathrm{d} s\right]^{\alpha /(\alpha+\beta)}
$$

where

$$
P_{0}=\left(b(\alpha+\beta) \alpha^{-1} t^{-1} \bar{u}^{-1 / \alpha}\right)^{\alpha /(\alpha+\beta)}>0 \text { and } a_{0}=\left((1+a) / P_{0}\right)^{(\alpha+\beta) / \alpha}>0
$$

The term $P_{0}$ reflects the base traffic pollution level for given preferences and technology, while $a_{0}$ relates this base pollution level, which is generated within the city, to the exogenous regional pollution, $a$. One can see that exposure to pollution is higher close to the CBD.

Urban fringe and land profiles. Farmers pay a constant and exogenous agricultural rent $R_{A}$, which is the opportunity cost of rent. The boundary of the city $r_{f}$ is the location where the bids of farmers and households equalize, i.e. where $\Psi(r)=R_{A}$. Thus, the urban equilibrium must satisfy $R\left(r_{f}\right)=R_{A}$ and $R(r)>R_{A}$ for all $r<r_{f}$. Under Cobb-Douglas preferences, expenses on housing consumption are equal to the share $\alpha$ of income net of commuting: $R(r) H(r)=\alpha(Y-t r)$. Expression (2.6) gives the following land rent profile

$$
R=\bar{u}^{-1 / \alpha}(Y-t r)^{1 / \alpha} P^{-\beta / \alpha}
$$

The land rent increases with the housing share in expenditure $\alpha$ and available income $Y-t r$ but decreases with higher utility in the rest of the world $\bar{u}$, commuting costs $t$ and the level of local pollution exposure $P(r)$.

We can now make explicit the dependence of the land rent and the fringe $r_{f}$ and discuss the existence of the urban equilibrium.

First, the city border $r_{f}$ is given by the city border condition, $R\left(r_{f}\right)=R_{A}$, and yields a unique value 


$$
r_{f}=\left(Y-(1+a)^{\beta} \bar{u} R_{A}^{\alpha}\right) / t
$$

which is smaller than $Y / t$ as in the standard urban model and validates the above assumption $r_{f}<Y / t$. The city border does not depend on the pollution technology parameter $b$. This is because there is no traffic and no traffic-induced exposure at the fringe but only regional pollution. The fringe distance, however, diminishes with regional pollution $a$, which is a rejoinder to results by Robson (1976) for stationary pollution sources and Verhoef and Nijkamp (2003) for city-wide pollution. As in the literature, the city border increases with larger income $Y$ and decreases with larger commuting cost $t$, external utility $\bar{u}$ and agricultural rent $R_{A}$. Note that the city is not empty if $r_{f}>0$; that is, $R_{A}<R_{A}^{*}$ where

$$
R_{A}^{*} \equiv\left(\frac{Y}{(1+a)^{\beta} \bar{u}}\right)^{1 / \alpha}
$$

Note that this could be due to a strong aversion $\beta$ to pollution exposure originating from regional pollution $a$.

Second, the gradient of the land rent is given by differentiating (2.9) so that

$$
\frac{\dot{R}}{R}=-\frac{1}{\alpha} \frac{t}{Y-t r}-\frac{\beta}{\alpha} \frac{\dot{P}}{P}
$$

The first negative term describes the land rent in absence of traffic-induced pollution exposure $(\dot{P}=0)$ or when there is no aversion to exposure $(\beta=0)$. The second term is positive since $\dot{P}<0$. It reflects the effect of traffic-induced pollution exposure, which falls with distance from the CBD. In Appendix A, we show that the land rent is a decreasing function of $r$ on $\left[0, r_{f}\right]$ if and only if $R_{A} \leq R_{A}^{* *}$ where

$$
R_{A}^{* *} \equiv \frac{\alpha}{\beta} \frac{1+a}{b} t
$$

For land rent to fall everywhere with distance from the CBD, the effects of traffic pollution $(b)$ should therefore not be too high compared to regional pollution and commuting costs $(a$ and $t$ ). If this condition does not hold, bid rents first decrease as one moves away from the CBD but then increase in the neighborhood of $r=r_{f}$.

The two conditions $R_{A} \leq R_{A}^{*}$ and $R_{A} \leq R_{A}^{* *}$ are sufficient and necessary 
for a unique urban equilibrium. When the two conditions hold, residential bid rents lie above $R_{A}$ for $r \in\left[0, r_{f}\right]$, which is consistent with the urban equilibrium. Otherwise, either the city is nil or the households' land bid rents lie below $R_{A}$ near the fringe. In case traffic pollution raises such that $R_{A}^{* *}$ falls below $R_{A}$, it harms all households who then bid for a lower land rent near the fringe. However, since the bid of households at the fringe is close to the agricultural rent, a stronger traffic-induced pollution exposure leads those households to lower their bid below the agricultural offer. Formally, the households' bid rent increases close to $r_{f}$ so that $R\left(r_{f}-d r\right)<R_{A}$ and $R\left(r_{f}\right)=R_{A}$, which is incompatible with an urban equilibrium.

The condition highlights the importance of regional pollution from sources other than traffic for the existence of an equilibrium.

Proposition 1. There exists a unique urban equilibrium if and only if $R_{A} \leq$ $\min \left\{R_{A}^{*}, R_{A}^{* *}\right\}$. Equilibrium land rents fall with distance from the center.

The equilibrium can be understood from the left hand side panel of Figure $2,{ }^{4}$ which displays the graphs of the land rent $R(r)$ for different values of $R_{A}$ and, therefore, for different values of $r_{f}$ since $R\left(r_{f}\right)=R_{A}$. The dashed curve depicts the land rent value in the absence of traffic-induced pollution $(b=0)$. The solid curves display the equilibrium land rents, which fall in every location. The value of the fringe distance $r_{f}$ and the outside land rent $R_{A}$ lie at the intersection between the solid and dashed curves. The upper solid curve displays the equilibrium land rent for the critical value $R_{A}=R_{A}^{* *}$. No urban equilibria exist for $R_{A}$ above this value. The dotted curves depict the households' bid rents in those cases. As those bids increase at the city fringe, farmers necessarily overbid households there.

In case the level of traffic pollution exposure is very high (higher $\beta$ ), households' aversion to traffic-induced pollution exposure results in a population shift towards the fringe such that the land rent does not fall at the fringe and no equilibrium is reached $\left(R_{A}<R_{A}^{* *}\right.$ does not hold). The trafficinduced pollution imposes a condition (not continuous) on the existence of urban equilibrium that is different from the condition imposed by global pollution. While the latter reduces households' net utility and binds when the

\footnotetext{
${ }^{4}$ The parameters of the figure are $\{\alpha, \beta, a, b, Y, \bar{u}\}=\left\{0.333333,0.5,1.3510^{-6}\right.$, 0.05, 30000., 42. $\}, \mathrm{Ra} \in\{0,90740741,120987654,151234568,181481481,211728395$, $241975309\}$.
} 
Figure 1: Equilibrium land rent and population density
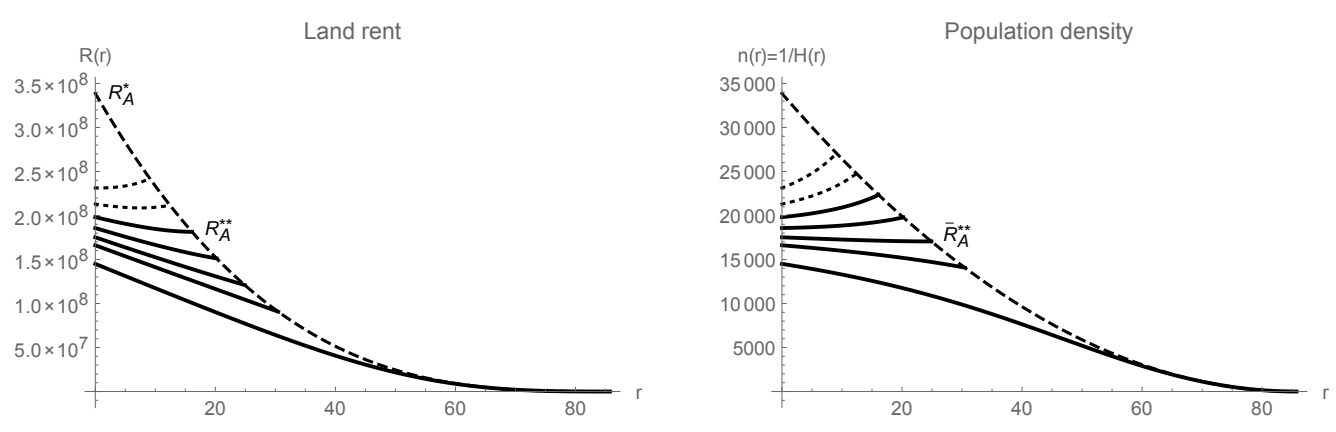

Note: The left hand side panel shows rent profiles and the right hand side panel the density profiles with respect to distance from the CBD for different values of agricultural rent $R_{A}$. The fringe distance lies at the intersection between the solid and dashed curves. Thick solid lines display urban equilibria, whereas dotted lines depict profiles in absence of urban equilibrium. The line close to $R_{A}^{* *}$ represents the land rent schedule equal to $R_{A}^{* *}$, which is the highest land rent for equilibrium. The curve of the density population related to $\bar{R}_{A}^{* *}$ is the one for which land rent is always decreasing.

city reaches a zero size, the former alters households' utility levels and bid rents in such a way that the land market cannot clear around the city border.

Population density and size. Population density $n(r)$ is directly derived from housing consumption and hence from pollution exposure according to $(2.6): n=1 / H=-\dot{P} / b$. The density is actually

$$
n(r)=\alpha^{-1} \bar{u}^{-1 / \alpha} P^{-\beta / \alpha}(Y-t r)^{(1-\alpha) / \alpha}
$$

Its properties depend on the convexity of the equilibrium pollution exposure $P$. The latter is a convex function of $r$ if $R_{A} \leq \bar{R}_{A}^{*}$ where

$$
\bar{R}_{A}^{*} \equiv(1-\alpha) \frac{\alpha}{\beta} \frac{1+a}{b} t
$$

with $\bar{R}_{A}^{*}<R_{A}^{* *}$ (see Appendix A). Otherwise, it is first convex and then becomes concave for locations close to $r_{f}$ (see Appendix A). Therefore, under $R_{A} \leq \bar{R}_{A}^{*}$, the population density $n$ decreases everywhere. Also, since this condition is more restrictive than condition (2.13), it guarantees the existence 
of an urban equilibrium. By contrast, under $R_{A}>\bar{R}_{A}^{*}$, the pollution exposure profile $P$ is convex for small $r$ and concave for $r$ close to the city fringe $r_{f}$. Then, if $\bar{R}_{A}^{*}<R_{A} \leq \min \left\{R_{A}^{*}, R_{A}^{* *}\right\}$, an urban equilibrium exists with non-monotonic population density. High opportunity costs of land reduce the spatial extent of the city such that the additional benefit from reduced pollution exposure obtained near the fringe can only be compensated by lower housing consumption. This effect is depicted in the right hand side panel of Figure 2, which plots the urban density profiles for the same parameters as in the left hand side panel. Density profiles depicted in the lower part of the figure are decreasing while the ones in the upper part are increasing with distance from the CBD. Equilibrium profiles are again displayed with solid lines while out-of-equilibrium density profiles are shown with dots.

From (2.14), we see that the density at the fringe is:

$$
n\left(r_{f}\right)=\alpha^{-1} \bar{u}^{-1}(1+a)^{-\beta} R_{A}^{1-\alpha}
$$

Traffic-induced pollution has no effect on the density at the fringe location because there is no traffic pollution at the fringe. By contrast, a larger global exogenous pollution reduces the equilibrium density at the fringe because households demand larger land plots to compensate for the disutility from pollution.

Proposition 2. The population density falls monotonically from the city center to the city fringe if $R_{A} \leq \bar{R}_{A}^{*}$ and is non-monotonic otherwise.

To sum up this section, traffic-induced pollution alters households' bid rents. Urban equilibria exist for a smaller set of parameters compared to a model without such pollution. In the presence of traffic-induced pollution, equilibrium population densities may be rising in the fringe neighborhood. Equilibrium land rent gradients nevertheless remain negative as in the classical theory of the monocentric city.

\section{Comparative statics}

We now study the impact of the exogenous model parameters of interest, namely vehicle technology, regional pollution, aversion to pollution exposure and transport costs. 
Clean vehicle technology $(b)$. Cleaner vehicle technologies reduce the vehicle emission factor $b$. However, while cleaner technologies diminish one's exposure to existing vehicles, they make the city more attractive and foster population migration and commuting traffic. As a result, the impact of the clean technology is mitigated by a larger flow of commuters. Thus, the impact of clean technology might be ambiguous.

Nevertheless this model shows that a lower emission factor $b$ causes lower equilibrium pollution exposure $P$ throughout the city. This is because, on the one hand, pollution exposure remains the same at the fringe location where $P\left(r_{f}\right)=1+a$ (independent of the city population), while the fringe distance $r_{f}$ is independent of $b$ due to (2.10). On the other hand, by (2.7), pollution exposure falls less rapidly with distance from the CBD as $b$ gets smaller. This property has an impact on the other variables. Indeed, from (2.14), we can see that the population density $n(r)$ increases with smaller $b$ through its effect on pollution exposure. The total population in the city, $N=\int_{0}^{r_{f}} n(r) d r$, then increases with cleaner vehicle technology. From (2.9), land rents increase with smaller $b$ while their gradients become steeper (see Appendix A).

Finally, by (2.15), cleaner vehicle technology raises the threshold $\bar{R}_{A}^{*}$. Consequently, a non-monotonic population density emerges only for a smaller set of parameters.

Proposition 3. Cleaner vehicle technologies (smaller b) reduce pollution exposure, increase the city population and its density throughout the city and do not affect the spatial extent of the city. They induce higher and steeper land rents everywhere. Non-monotonic population density profiles emerge for a smaller set of parameters.

Regional pollution $(a)$. Lower regional pollution $a$ has a direct effect on utility for all residents. However, this effect is mitigated by the indirect effect of traffic-induced pollution. Lower regional pollution indeed makes residence in the city more attractive and increases its geographical extent (see (2.10)). As a consequence, more residents commute from locations farther from the CBD so that regional pollution is partly substituted by trafficinduced pollution. This balance is apparent in expression (2.8) where a lower $a$ decreases $a_{0}$ and increases $r_{f}$. However, it can be shown that the direct effect dominates so that lower regional pollution $a$ reduces pollution exposure 
$P$ everywhere (see Appendix A). Observe that since traffic-induced pollution is nil at the fringe and implies no exposure there, regional pollution is the only pollution component that determines the spatial extent of the urban area. By (2.14), population densities increase everywhere while the total population $N$ expands. By (2.9), land rents become higher. However, land rent gradients become flatter with lower a (see Appendix A).

For the purpose of empirical analysis, it is important to identify the direction of the effects of regional versus traffic-induced pollution. The first two rows of Table 1 summarize the above results. One can observe that those pollution sources differ by their effects on the fringe distance, fringe population density and land rent gradient steepness. In addition, from the previous section, they have a different effect on population density profiles.

Table 1: Comparative statics

\begin{tabular}{|c|c|c|c|c|c|c|c|c|}
\hline Effect of & & $X=$ & $r_{f}$ & $P(r)$ & $R(r)$ & $n(r)$ & $N$ & $|R(r)|$ \\
\hline emission per vehicle & $\mathrm{d} X / \mathrm{d} b$ & & 0 & + & - & - & - & - \\
\hline regional pollution & $\mathrm{d} X / \mathrm{d} a$ & & - & + & - & - & - & + \\
\hline $\begin{array}{l}\text { aversion to pollution } \\
\text { exposure }\end{array}$ & $\mathrm{d} X / \mathrm{d} \beta$ & & - & - & - & - & - & nd \\
\hline unit transport cost & $\mathrm{d} X / \mathrm{d} t$ & & - & - & + & + & - & nd \\
\hline
\end{tabular}

Note: A marginal increase in an exogenous parameter (rows) causes an increase $(+)$ or decrease (-) in the endogenous model variable $X$ (columns); (nd : not discussed).

Proposition 4. The effect of a lower traffic-induced air pollution is different from a lower regional pollution as it does not impact the geographical extent and population density at the fringe. It also induces a rise in the land rent gradient and can lead to a non-monotonic population density.

Aversion to pollution exposure $(\beta)$. A stronger aversion to pollution (higher $\beta$ ) reflects the citizens' increasing preferences for air quality and their stronger values for quality of life and health. It can readily be seen from (2.10) that a higher $\beta$ diminishes the city extent $r_{f}$. It can be shown that pollution exposure $P$ decreases with larger $\beta$. This is because, from (2.7), the pollution exposure gradient $\dot{P}$ is smaller with larger $\beta$ as $P^{\beta / \alpha}$ rises with larger $r$ and because pollution exposure integrates $P$ from $r$ to a smaller $r_{f}$. By (2.16), a stronger aversion to pollution exposure diminishes the population density at the fringe. By (2.9) and (2.14), the impact on population 
density and land rent depends on $P^{\beta / \alpha}$. It can be shown that $P^{\beta / \alpha}$ rises with higher $\beta$ in the case of both regional pollution or traffic-induced pollution (see Appendix A). As a result, a stronger aversion to pollution exposure decreases the population density and land rent. By the same argument, the total population also falls.

Note that the parameter $\beta$ can also be interpreted as a households' perception of the health risk associated with pollution rather than a simple aversion to pollution exposure. The perception of such a risk is a key aspect identified in the social science literature (Gatersleben and Uzzell, 2000; Istamto et al., 2014). Hence an upward bias in the perception of health risk caused by air pollution raises the parameter $\beta$ and amplifies the above effects.

Unit transport costs $(t)$. In this model, the unit transport cost $t$ captures several factors such as gasoline price, gasoline tax, per-km tax and a household's opportunity cost of travel time (lost leisure, child care cost...). Since transport costs discourage households to commute long distances, they help reduce pollution emissions. From (2.10) we see that higher transport costs move the urban fringe closer to the CBD. Also, higher transport costs reduce the pollution everywhere in the city. They indeed decrease the vehicle traffic everywhere, which implies a smaller (absolute value of the) gradient for the pollution exposure $P$ (see (2.7)). Since the pollution exposure integrates this gradient from $r$ to a smaller fringe distance $r_{f}$, the pollution exposure $P$ is necessarily smaller for all $r$. In turn, by (2.9) and (2.14), the lower pollution exposure raises the population density and land rent everywhere, except at the city fringe where the population density and land rent remain the same. Finally, total population falls. Those results are reported in Table 1 .

Vehicle fuel consumption efficiency $(t, b)$. It is of interest to study the impact of more energy efficient vehicles as it has occurred over the last four decades. Lower fuel consumption per distance unit leads not only to lower transport cost $t$ but also to lower pollution emission per vehicle $b$. That is, we have a simultaneous fall in $t$ and $b$. Lower fuel costs entice households to commute more and reside further away from the center whereas lower exposure makes the city center more attractive. In Table 3, we can deduce that the city population $N$ and its geographical extent $r_{f}$ expand. Lower fuel costs decrease land rents but lower emissions increase them everywhere. As 
a result, the net effect on land rent is ambiguous. The effect on population density and exposure to pollution at each location is also ambiguous. In other words, vehicles pollute less but the traffic becomes more intense.

\section{Optimal city structure}

In equilibrium, households do not consider the consequences of their commuting decisions on others' exposure to pollution. We now characterize the first-best optimum where a planner internalizes the pollution exposure externality. Analyses of both optimum pricing schemes and their effects on optimum city structures in the context of traffic-induced externalities are dominantly found in congestion literature within discrete (Brueckner, 2014) or continuous space (Tikoudis et al., 2015; Verhoef, 2005; Vickrey, 1969). In the context of traffic-induced air pollution, only McConnell and Straszheim (1982) and Robson (1976) compare equilibrium and optimum city structures. The former use numerical simulation while the latter does not explicitly analyze the nature of the optimal policy rule. We extend this literature by solving and discussing a first-best optimum over a continuous space.

The planner's maximization problem. In the present open city framework, following e.g. Fujita (1989) (p.65) the objective of the planner is to maximize the aggregate land rent $(A L R)$ to the land owners and, thus, the total economic outcome given the endogenous traffic-induced pollution exposure and migration. The planner's problem is

$$
\begin{aligned}
\max _{\left\{H(\cdot), Z(\cdot), n(.), P(.), r_{f}\right\}} A L R & =\int_{0}^{r_{f}}\left[(Y-t r-Z(r)) n(r)-R_{A}\right] \mathrm{d} r \\
\text { s.t. } & \\
P(r) & =1+a+b \int_{r}^{r_{f}} n(r) \mathrm{d} r \\
\bar{u} & \leq U[(Z(r), H(r), P(r)] \\
n(r) & =1 / H(r)
\end{aligned}
$$

We can differentiate and replace the integral equality (4.2) by the conditions $\dot{P}(r)=-b n(r)$ and $P\left(r_{f}\right)=1+a$. The problem then becomes an optimal control problem to which we can apply Pontryagin's maximization principle with a free final condition at $r=0$. In the following, we drop the reference 
for the location $r$ on the control and state functions $(H, Z, n, P)$ whenever it brings no confusion.

The generalized Hamiltonian $\mathcal{H}$ for the above problem writes as

$$
\mathcal{H}(Z, H, P, \mu, r)=(Y-t r-Z) / H-R_{A}-b \mu / H
$$

after $n$ is replaced by $1 / H$ using (4.4). The control variables $Z$ and $H$ satisfy the migration constraint (4.3) and $\mu$ is the co-state variable of the motion equation $\dot{P}=-b / H$ associated with the state variable $P$. The co-state variable $\mu$ is a function of distance $r$ from the CBD and measures the marginal impact that an additional household induces on others when it locates at $r$. The co-state variable $\mu(r)$ then reflects the shadow cost of traffic-induced pollution exposure to the residents located in the interval $[0, r)$. The necessary conditions for the optimum are given by

$$
\begin{aligned}
\left(H^{*}, Z^{*}\right) & \in \arg \max _{H, Z} \mathcal{H}(Z, H, P, \mu, r) \text { s.t. } U(Z, H, P) \geq \bar{u} \\
\dot{\mu} & =-\frac{\partial}{\partial P} \mathcal{H}\left(Z^{*}, H^{*}, P, \mu, r\right) \quad \text { and } \quad \mu(0)=0 \\
R_{A} & =\left[Y-t r_{f}-Z\left(r_{f}\right)-b \mu\left(r_{f}\right)\right] / H\left(r_{f}\right)
\end{aligned}
$$

(e.g. Seiderstad and Sydsaeter (1987), p.276). Condition (4.6) expresses the optimal spatial balance in traffic-induced pollution. Changes in pollution level $P(r)$ at location $r$ should not raise utility and therefore land value at $r$ more than they diminish the social cost of the traffic-induced pollution they generate on the other residents. Under Condition (4.7) the rent is equal to the opportunity cost of land at the fringe. Although the above objective function is not concave, we show in Appendix B that it accepts a unique maximizer as the interior solution that we discuss below.

Consumption. The optimal allocation of housing $H$ and composite good $Z$ follows from the same argument as for the equilibrium, except for the presence of the shadow cost $\mu$ :

$$
\begin{aligned}
H & =\alpha \bar{u}^{1 / \alpha} P^{\beta / \alpha}(Y-t r-b \mu)^{-(1-\alpha) / \alpha} \\
Z & =(1-\alpha)(Y-t r-b \mu)
\end{aligned}
$$

In the absence of traffic-induced pollution $(b=0)$, those expressions match the equilibrium conditions so that the equilibrium is efficient, which is rem- 
iniscent of the traditional theory of land markets (e.g. Fujita, 1989; Fujita and Thisse, 2002).

The traffic-induced exposure shadow cost $\mu$ solves condition (4.6). Using the last expressions, condition (4.6) writes as $\dot{\mu}=\beta \alpha^{\frac{\alpha}{1-\alpha}} \bar{u}^{\frac{1}{1-\alpha}} n^{1 /(1-\alpha)}$ $P^{(\alpha+\beta-1) /(1-\alpha)}$ (see also Appendix B). Since $n$ and $P$ are positive functions, we have $\dot{\mu}>0$ and

$$
\mu(r)=\beta \alpha^{\frac{\alpha}{1-\alpha}} \bar{u}^{\frac{1}{1-\alpha}} \int_{0}^{r}(H(s))^{-1 /(1-\alpha)}(P(s))^{(\alpha+\beta-1) /(1-\alpha)} \mathrm{d} s
$$

which is nil at the city center and positive at all other locations. The trafficinduced exposure shadow cost $\mu$ increases as $r$ rises to $r_{f}$. Households living further away from the CBD have a longer commute and generate more exposure to pollution for households located on their route to work. Thus, the allocation of households in suburban locations is more costly to society than an allocation in central areas.

Land value and fringe. In the first-best, the planner increases the city extent as long as the value of land in the city lies above its opportunity cost $R_{A}$. That is, not only must condition (4.7) hold at $r=r_{f}$ but also its right-hand side must fall with $r$ in this neighborhood to have a maximum aggregate land rent. Hence, on the one hand, using (4.7) and the above values for $H$ and $Z$, the first-best fringe distance can be computed as

$$
r_{f}=t^{-1}\left[Y-(1+a)^{\beta} \bar{u} R_{A}^{\alpha}-b \mu\left(r_{f}\right)\right]
$$

Since $\mu \geq 0$, the fringe distance is smaller in the first-best allocation than in the equilibrium. The planner reduces the endogenous traffic pollution exposure by reducing city size. The traffic-induced exposure shadow cost at the fringe depends on pollution levels and population density distribution within the city. The higher the pollution (thus, population exposure) within the city, the smaller the spatial extent of the first-best. Note that the city shall not be empty if $r_{f}>0$; i.e. $R_{A}<R_{A}^{o}$ where $R_{A}^{o}$ is the land opportunity cost that solves the above equation for $r_{f}=0$ and $\mu\left(r_{f}\right)=\mu(0)=0$. One computes

$$
R_{A}^{o} \equiv\left(\frac{Y}{(1+a)^{\beta} \bar{u}}\right)^{1 / \alpha}
$$


If $R_{A} \geq R_{A}^{o}$ there is not enough surplus to develop a city. One can see that $R_{A}^{o}=R_{A}^{*}$ so that the condition for a non-empty city is the same for the first-best and the equilibrium. This is simply because when the city begins to develop from a zero size, it incurs no traffic-induced pollution.

On the other hand, the land value should fall with $r$ at $r=r_{f}$. For consistency we denote the first-best land value as $R$, as defined in (2.9). The latter falls with $r$ if and only if

$$
\frac{\dot{R}}{R}=-\frac{1}{\alpha} \frac{t+b \dot{\mu}}{Y-t r-b \mu}-\frac{\beta}{\alpha} \frac{\dot{P}}{P}<0
$$

which parallels the condition for convex land rents in the equilibrium. It is shown in Appendix B that this condition is verified at $r=r_{f}$ for any $R_{A}<R_{A}^{o o}$ such that

$$
R_{A}^{o o} \equiv \frac{\alpha}{\beta} \frac{1+a}{b}\left(t+b \dot{\mu}\left(r_{f}\right)\right)
$$

because $\dot{\mu}\left(r_{f}\right)$ is strictly positive. The planner may decide not to develop a city if the opportunity costs of land are too high $\left(R_{A}>R_{A}^{o o}\right)$.

Proposition 5. The planner develops a city if and only if $R_{A}<\min \left\{R_{A}^{o}, R_{A}^{o o}\right\}$. Under this condition, it sets a city with a smaller fringe distance than in the equilibrium.

Since $R_{A}^{o}=R_{A}^{*}$ and $R_{A}^{o o}>R_{A}^{* *}$, the planner develops a city for opportunity costs of land that are higher than those for which a city emerges in equilibrium. This is because the planner corrects for the traffic-induced pollution externality and raises the net surplus and aggregate land value.

The left hand panel of Figure 4 displays first-best land values for the same parameters as in Figure 2. In this figure the land value falls with distance from the center. While the aggregate land value (ALR) of the first-best is larger by definition, it cannot be theoretically said whether first-best land values are higher or lower at every location than the equilibrium ones.

Spatial distribution of pollution exposure. The spatial distribution of pollution exposure is obtained by solving the differential equation $\dot{P}=-b / H$ with the initial conditions $P\left(r_{f}\right)=1+a$. Plugging in the above 
Figure 2: First-best land value and population density.
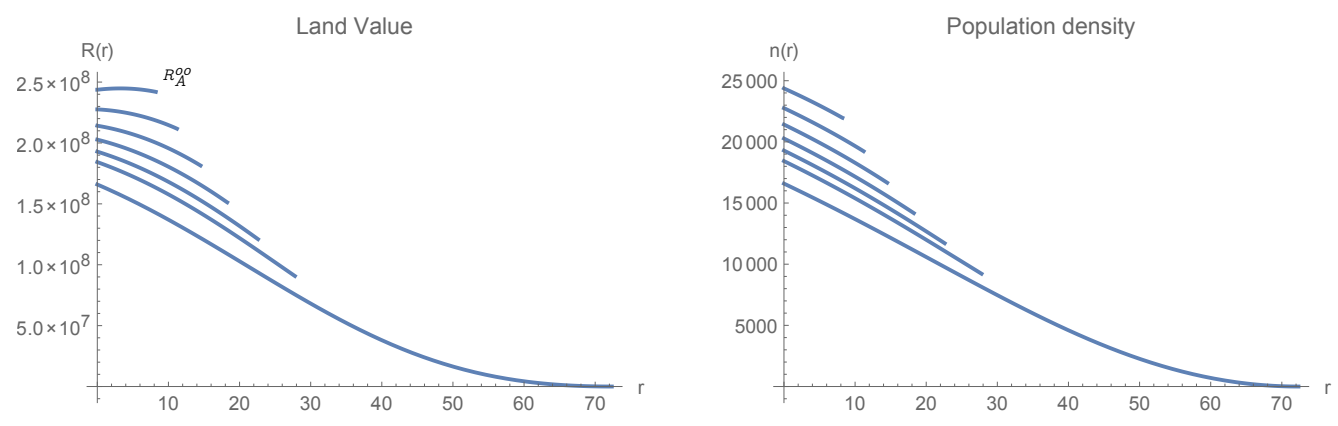

Note: The left hand panel displays first-best land rent values and the right hand panel shows the first-best population density distributions with traffic-induced pollution $(b>0)$.

values of $H$ and reshuffling allows us to integrate the differential equation as for (2.7) to get

$$
P(r)=P_{0}\left[a_{0}+\frac{t}{\alpha} \int_{r}^{r_{f}}(Y-t s-b \mu)^{(1-\alpha) /(\alpha)} \mathrm{d} s\right]^{\alpha /(\alpha+\beta)}
$$

with $P_{0}$ and $a_{0}$ defined as in the previous section. The integral is smaller in the first-best than in the equilibrium because the fringe distance is smaller and the term $b \mu$ reduces the value of the integrand. Thus, exposure is lower at each location in the first-best than in the equilibrium city.

Proposition 6. The first-best allocation has lower pollution exposure levels at all locations.

Population density. The density is actually computed as

$$
n(r)=\alpha^{-1} \bar{u}^{-1 / \alpha} P^{-\beta / \alpha}(Y-t r-b \mu)^{(1-\alpha) / \alpha}
$$

which is analogous to the equilibrium expression except for the presence of the term $b \mu$. We readily see that the presence of $b \mu>0$ in (4.15) decreases densities while lower pollution increases them. Since lower densities decrease pollution exposure, it is not a priori clear whether densities are larger or lower in the first-best. Yet, at the city center $r=0$, the density $n(0)$ is higher in 
the first-best because $P(0)$ is lower in the first-best, while $\mu(0)=0$. The residents at the center do not need to be allocated as many land plots as in the equilibrium to compensate for the negative externality of traffic-induced air pollution. Similarly, at the city fringe $r=r_{f}$, the density $n\left(r_{f}\right)$ is lower in the first-best as $P\left(r_{f}\right)=1+a$ and $\mu\left(r_{f}\right)>0$. There, pollution exposure is the same as in the equilibrium, while the planner reduces the number of residents to reduce city traffic.

Proposition 7. Population density is higher at the city center but lower at the city fringe in the first-best.

The right hand panel of Figure 4 presents the first-best density profile (blue solid curve). It is a decreasing function of the distance from the city center. One can observe that the density levels and gradients are markedly lower in the presence of traffic-induced pollution. Figure 4 further compares the first-best density profiles (blue solid curves) with the equilibrium density (solid black curves). Again dotted curves present the solutions for $R_{A}>R_{A}^{* *}$ and the black dashed curve the density profiles in the absence of trafficinduced pollution $(b=0)$. The first-best allocation leads to a higher density at the center and a lower density at the fringe. This suggests a pollution shift from the suburb to the center.

Decentralized policy. In the above, the planner sets the allocation of households' consumptions and their locations. The planner can nevertheless decentralize its plan by imposing a localized lump-sum tax from households that is equal to $b \mu(r)$ (see Appendix B). The tax reduces the income such that not only the demand for the consumption good matches the lower optimal consumption, but also such that the demand for land use and the pollution exposure level correspond to optimal levels. The tax is not budget balanced since it is positive at all locations.

Proposition 8. The planner can decentralize the first-best allocation through a localized lump-sum tax that increases with distance.

The pollution exposure externality takes place on commuting routes between each commuter and the many residents on the route. Since pollution is a local public bad, one expects the planner to tax the commuters at each place of pollution and according to the number of exposed households, which 
Figure 3: Equilibrium and first-best population density distributions

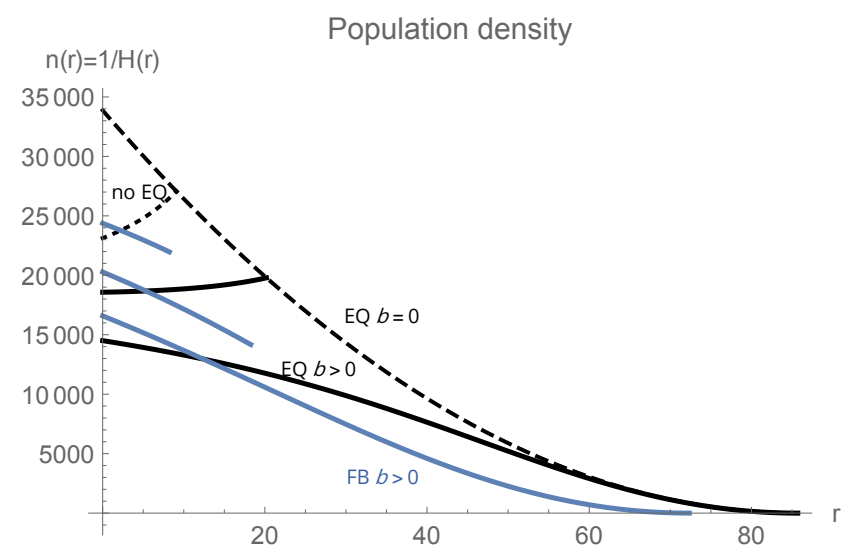

Note: The figure compares the equilibrium (black) and first-best (blue) population density distributions with traffic-induced pollution (solid lines). The dashed black line shows the equilibrium density distribution without traffic-induced pollution $(b=0)$. Dotted lines show the solutions for the land rent and density when $R_{A}$ is larger than $\min \left\{R_{A}^{*}, R_{A}^{* *}\right\}$ and $\min \left\{R_{A}^{o}, R_{A}^{o o}\right\}$.

seems to be a difficult task. Nevertheless, the planner has the simpler solution of intervention at the residence place of emitters. This is because the spatial distribution of the population fully determines both the spatial distributions of pollution emission and exposure. The lump-sum tax at the residence place is then a sufficient instrument to implement the optimal policy.

Figure 4 shows the value of the optimal localized lump-sum tax. The value rises nearly linearly with commuting distance in locations that are not too far from the center. It however reaches a ceiling in locations that are very distant from the center. Practically, this suggests the application of a tax per traveled kilometre in central locations and in small cities and a tax per residence in the outer locations of large cities.

\section{Discussion and conclusion}

In this paper we have discussed the properties of the urban equilibrium and first-best optimum when traffic-induced air pollution is endogenous. We show that the aversion to pollution exposure reduces the urban population size and results in flatter or non-monotonic population density distributions: 
Figure 4: Localized lump-sum tax.

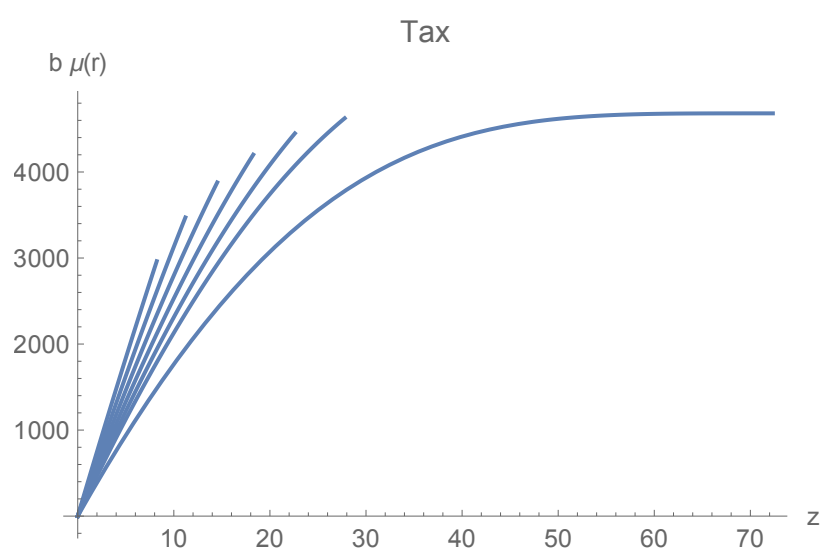

Note: $b \mu(r)$ is in monetary terms and represents the same parameters as in Figure 2.

the population density in locations near the center is reduced while locations farther away from the center retain high population densities since households prefer to move outward to escape air pollution exposure. Our equilibrium analysis shows that dispersion from central areas is desired by households in the case of local traffic-induced air pollution. By contrast, regional air pollution has no such effect. In this respect, our analysis emphasizes that the spatial extent at which residents consider air pollution does matter in the determination of the city population size and density distribution.

The first-best policy consists of a localized lump-sum tax that increases with distance from the centre. It leads to a smaller pollution exposure throughout the city and a smaller city extent compared to the equilibrium. Densities at the center are higher and densities at the fringe lower. It also permits the development of cities for larger set of parameters (e.g. larger opportunity cost of land). Nonetheless, the first-best tax yields a surplus to the planner. The study of a second-best optimum where the planner has a balanced budget would be of interest for future research.

Our results suggest that localized policies are essential in managing trafficinduced pollution. Indeed, aggregate constraints on population size and urban extent are unlikely to induce the changes in urban land rents and population densities that make the equilibrium closer to the first-best. Rather, we show that a localized lump-sum tax can be an appropriate instrument. 
Further, we have discussed the effects of cleaner vehicle technologies and more fuel efficient fuel consumption on urban structures. Future research should address the question of the interaction between households' incomes and those effects. While this paper focuses on the impact of localized and aggregate pollutants, it would also be interesting to consider the interaction of pollutants with larger and smaller diffusion distances.

Furthermore, we can consider the lack of information on the health danger of traffic-induced pollution. If people are ignorant of health impacts due to traffic-induced air pollution, our results show that cities are too dense and too populated. It is important to bear this in mind when applying other urban policies like anti-sprawl policies that actually further densify city centers.

\section{Acknowledgements}

The authors would like to thank Philip Ushchev for his great help in the proof of the first-best global maximum. The authors also thank Rémi Lemoy for supporting mathematical discussions.

\section{References}

Alonso, W., 1964. Location and land use: Towards a general theory of land rent. Harvard University Press, Cambridge, Mass.

Anas, A. and Xu, R., 1999. Congestion, Land Use, and Job Dispersion: A General Equilibrium Model. Journal of Urban Economics, volume 45(3):451-473.

Arnott, R., Hochman, O. and Rausser, G.C.G., 2008. Pollution and land use: Optimum and decentralization. Journal of Urban Economics, volume 64(2):390-407.

Bickerstaff, K. and Walker, G., 2001. Public understandings of air pollution: the 'localisation' of environmental risk. Global Environmental Change, volume 11:133-145.

Boadway, R., Song, Z. and Tremblay, J., 2011. Non-cooperative Pollution Control in an Inter-jurisdictional Setting. Regional Science and Urban Economics, volume 43:783-796. 
Borrego, C., Martins, H., Tchepel, O., Salmim, L., Monteiro, A. and Miranda, A.I., 2006. How urban structure can affect city sustainability from an air quality perspective. Environmental Modelling Software, volume 21(4):461-467.

Brueckner, J.K., 2014. Cordon Tolling in a City with Congested Bridges.

Chay, K.Y. and Greenstone, M., 2005. Does Air Quality Matter? Evidence from the Housing Market. Journal of Political Economy, volume 113(227):376-424.

Colvile, R.N., Hutchinson, E.J., Mindell, J. and Warren, R., 2001. The transport sector as a source of air pollution. Atmospheric Environment, volume 35:1537-1565.

Cramer, J.C., 2002. Population Growth and Local Air Pollution: Methods, Models and Results. Population and Development Review, volume 28(2002):22-52.

De Ridder, K., Lefebre, F., Adriaensen, S., Arnold, U., Beckroege, W., Bronner, C., Damsgaard, O., Dostal, I., Dufek, J., Hirsch, J., Intpanis, L., Kotek, Z., Ramadier, T., Thierry, A., Vermoote, S., Wania, A., Weber, C. and Ridder, K.D., 2008. Simulating the impact of urban sprawl on air quality and population exposure in the German Ruhr area. Part I: Reproducing the base state. Atmospheric Environment, volume 42(30):7070-7077. doi: 10.1016/j.atmosenv.2008.06.044.

EEA, 2014. Air quality in Europe - 2014 report. Technical Report 5, European Environment Agency.

Fisch, O., 1975. Externalities and the Urban Rent and Population The Case of Air Pollution. Journal of Environmental Economics and Management, volume 2:18-33.

Fowler, D., Brunekreef, B., Fuzzi, S., Monks, P., Sutton, M., Brasseur, G., Friedrich, R., Passante, L. and Mingo, J., 2013. Air quality. Review. Research findings in support of the EU. Technical report, European Commission.

Fujita, M. and Thisse, J.F., 2002. Economics of Agglomeration. Cities, Industrial Location, and Regional Growth. Cambridge University Press. 
Fujita, M., 1989. Urban Economic Theory. Cambridge University Press, Cambridge.

Gaigné, C., Riou, S. and Thisse, J.F., 2012. Are compact cities environmentally friendly? Journal of Urban Economics, volume 72(23):123 - 136. doi:http://dx.doi.org/10.1016/j.jue.2012.04.001.

Gatersleben, B. and Uzzell, D., 2000. The Risk Perception of TransportGenerated Air Pollution. IATSS Research, volume 24(1):30-38.

Henderson, J., 1977. Externalities in a spatial context: The case of air pollution. Journal of Public Economics, volume 7:89-110.

Istamto, T., Houthuijs, D. and Lebret, E., 2014. Willingness to pay to avoid health risks from road-traffic-related air pollution and noise across five countries. Science of The Total Environment, volume 497498(0):420 429. doi:http://dx.doi.org/10.1016/j.scitotenv.2014.07.110.

Jerrett, M., Arain, A., Kanaroglou, P., Beckerman, B., Potoglou, D., Sahsuvaroglu, T., Morrison, J. and Giovis, C., 2005. A review and evaluation of intraurban air pollution exposure models. Journal of Exposure Analysis and Environmental Epidemiology, volume 15:185-204.

Kingham, S., Briggs, D., Elliott, P., Fischer, P. and Lebret, E., 2000. Spatial variations in the concentrations of trafc-related pollutants in indoor and outdoor air in Hudderseld, England. Atmospheric Environment, volume 34:905-916.

Kyriakopoulou, E. and Xepapadeas, A., 2013. Environmental policy, first nature advantage and the emergence of economic clusters. Regional Science and Urban Economics, volume 43(1):101-116. doi: 10.1016/j.regsciurbeco.2012.05.006.

Lange, A. and Quaas, M., 2007. Economic Geography and the Effect of Environmental Pollution on Agglomeration. The B.E. Journal of Economic Analysis \& Policy, volume 7(4).

Lera-López, F., Faulin, J. and Sánchez, M., 2012. Determinants of the willingness-to-pay for reducing the environmental impacts of road transportation. Transportation Research Part D Transport and Environment, volume 17:215-220. 
Manins, P.C., Cope, M.E., Hurley, P.J., Newton, P.W., Smith, N.C. and Marquez, L.O., 1998. The impact of urban development on air quality and energy use. Proceedings of the 14th International Clean Air and Environment Conference, Melbourne, pp. 331-336.

Marshall, J., Mckone, T., Deakin, E. and Nazaroff, W., 2005. Inhalation of motor vehicle emissions: effects of urban population and land area. Atmospheric Environment, volume 39(2):283-295.

Martins, H., 2012. Urban compaction or dispersion? An air quality modelling study. Atmospheric Environment, volume 54:60-72. doi: 10.1016/j.atmosenv.2012.02.075.

McConnell, V.D. and Straszheim, M., 1982. Auto pollution and congestion in an urban model: An analysis of alternative strategies. Journal of Urban Economics, volume 11(1):11-31.

Proost, S. and Dender, K.V., 1998. Effectiveness and welfare impacts of alternative polices to address atmospheric pollution in urban road transport. CES-Discussion paper series DPS.

Rauscher, M., 2009. Concentration, separation, and dispersion: Economic geography and the environment. Thünen-Series of Applied Economic Theory, (109).

Regnier, C. and Legras, S., 2014. Urban structure and environmental externalities. Working Paper INRA UMR 1041 CESAER, volume 2.

Robson, A., 1976. Two models of urban air pollution. Journal of Urban Economics, volume 284(May 1974):264-284.

Schindler, M. and Caruso, G., 2014. Urban compactness and the trade-off between air pollution emission and exposure: Lessons from a spatially explicit theoretical model. Computers, Environment and Urban Systems, volume 45:13-23.

Seiderstad, A. and Sydsaeter, K., 1987. Optimal Control Theory with Economic Applications. Elsevier Science Publisher.

Smith, V.K. and Huang, J.C., 1995. Can Markets Value Air Quality? A Meta-Analysis of Hedonic Property Value Models. Journal of Political Economy, volume 103(1):209-227. 
Tikoudis, I., Verhoef, E.T. and van Ommeren, J.N., 2015. On revenue recycling and the welfare effects of second-best congestion pricing in a monocentric city. Journal of Urban Economics. doi:10.1016/j.jue.2015.06.004.

Van Marrewijk, C., 2005. Geographical Economics and the Role of Pollution on Location. Tinbergen Institute Discussion Paper, volume 018/2.

Verhoef, E. and Nijkamp, P., 2003. Externalities in the Urban Economy. Tinbergen Institute Discussion Paper, volume 2003-078(3).

Verhoef, E.T., 2005. Second-best congestion pricing schemes in the monocentric city. Journal of Urban Economics, volume 58(3):367-388. doi: 10.1016/j.jue.2005.06.003.

Vickrey, W.S., 1969. Congestion theory and transport investment. The American Economic Review, volume 59(2):251-260. ISSN 00028282.

WHO, 2014. Air Quality and Health. WHO Media Centre, Fact Sheet N. 313. http://www. who.int/mediacentre/factsheets/fs313/en/. [Online; accessed 11-January-2016].

Zhang, Y.L. and Cao, F., 2015. Fine particulate matter (PM2.5) in China at a city level. Scientific Reports, volume 5(2014):14884. doi: $10.1038 /$ srep14884.

\section{Appendix A: Equilibrium}

\section{Land rent and equilibrium uniqueness}

Let us define the land rent as $R\left(r, r_{f}\right)$. We can simplify (2.12) as

$$
\frac{\dot{R}}{R}=-\frac{1}{\alpha} \frac{t}{Y-t r}\left[1+\frac{-\beta}{\alpha+\beta} \frac{(Y-t r)^{\frac{1}{\alpha}}}{(Y-t r)^{\frac{1}{\alpha}}-\left(Y-t r_{f}\right)^{\frac{1}{\alpha}}+a_{0}}\right]
$$

It is negative for $r \in\left[0, r_{f}\right]$ if and only if

$$
(Y-t r)^{\frac{1}{\alpha}} \geq \frac{\alpha+\beta}{\alpha}\left[\left(Y-t r_{f}\right)^{\frac{1}{\alpha}}-a_{0}\right]
$$

Since the LHS is a decreasing function of $r$, the land rent is a convex function of $r \in\left[0, r_{f}\right]$. There are at most two roots for the equation $R\left(r, r_{f}\right)=R_{A}$. 
Only the first root is compatible with the equilibrium condition $R\left(r_{f}, r_{f}\right)=$ $R_{A}$ and $R\left(r, r_{f}\right) \geq R_{A}$ for all $r<r_{f}$. Hence, when it exists, the equilibrium is unique. Evaluating the above condition at $r=r_{f}$ yields

$$
a_{0} \geq \frac{\beta}{\alpha+\beta}\left(Y-t r_{f}\right)^{\frac{1}{\alpha}}
$$

Using the expression of $r_{f}$ and replacing $a_{0}$ and $P_{0}$ by their values gives $R_{A} \leq R_{A}^{* *}$ where $R_{A}^{* *}=\frac{\alpha}{\beta} \frac{(1+a)}{b} t$.

\section{Convexity of $P(r)$}

Differentiating (2.7) and reshuffling yields

$$
P^{\frac{\beta}{\alpha}} \ddot{P}=b(1-\alpha)^{\frac{1-\alpha}{\alpha}+1} t(Y-r t)^{\frac{1-\alpha}{\alpha}-1} \alpha^{-1} u^{-\frac{1}{\alpha}}-\beta \mathrm{P}^{\frac{\beta}{\alpha}-1} \dot{P}^{2} \alpha^{-1}
$$

with $\dot{P}=-b n$. Replacing $n(r), P_{0}$ and $c_{0}$ and $r_{f}$ with their values, we find that $\ddot{P}$ is positive at the fringe if and only if

$$
R_{A} \leq \bar{R}_{A}^{*}=(1-\alpha) \frac{\alpha}{\beta} \frac{(a+1)}{b} t
$$

\section{Comparative statics}

Land rent gradients

We prove the effect of $a$ and $b$ on land rent gradients. Differentiating (2.8) we get

$$
\begin{aligned}
\frac{\dot{P}}{P} & =\frac{\alpha}{\alpha+\beta} \frac{\mathrm{d}}{\mathrm{d} r} \ln \left[(Y-t r)^{1 / \alpha}-\left(Y-t r_{f}\right)^{1 / \alpha}+a_{0}\right] \\
& =-\frac{t}{\alpha+\beta} \frac{(Y-t r)^{1 / \alpha-1}}{(Y-t r)^{1 / \alpha}-\left(Y-t r_{f}\right)^{1 / \alpha}+a_{0}}
\end{aligned}
$$

Note that $a_{0}$ is an increasing function of $a$ and a decreasing function of $P_{0}$ while $P_{0}$ is an increasing function of $b$. Therefore, $P / P$ falls for higher $a$ and lower $b$. The (negative) land rent gradient $R / R$ therefore becomes steeper for higher $a$ and lower $b$. 
Aversion to pollution exposure $\beta$

We show that $P^{\beta / \alpha}$ rises with higher $\beta$. If $a>b=0$, we have $P^{\beta / \alpha}=$ $(1+a)^{\beta / \alpha}$, which rises with $\beta$.If $a=0<b$, we have

$$
P^{\frac{\beta}{\alpha}}=\left[1+b \frac{\alpha+\beta}{\alpha^{2}} \bar{u}^{-1 / \alpha} \int_{r}^{r_{f}}(Y-t s)^{(1-\alpha) / \alpha} d s\right]^{\frac{\beta}{\alpha+\beta}}
$$

where $r_{f}=t^{-1}\left(Y-\bar{u} R_{A}^{\alpha}\right)$ is independent of $\beta$. It can be checked that the latter expression also increases with higher $\beta$.

Regional pollution a

We show that a lower global emission factor $a$ causes lower equilibrium pollution exposure $P(r)$ everywhere in the city: $(\mathrm{d} / \mathrm{d} a) \ln P(r)>0$. Indeed, substituting $\operatorname{tr}$ by $z$, we get $P(r)=P_{0}\left[a_{0}+B(t r)\right]^{\alpha /(\alpha+\beta)}$ where $P_{0}$, $B\left(z, z_{f}\right)=\frac{1}{\alpha} \int_{z}^{z_{f}}(Y-x)^{(1-\alpha) / \alpha} d x$ and where $z_{f} \equiv t r_{f}$ falls with $a$ by $(2.10)$. Noting that $\mathrm{d} P_{0} / \mathrm{d} a=0$, we compute

$$
\begin{aligned}
\frac{\mathrm{d}}{\mathrm{d} a} \ln P(r) & =\frac{\alpha}{\alpha+\beta} \frac{\mathrm{d}}{\mathrm{d} a} \ln \left[a_{0}+B\left(r, z_{f}\right)\right] \\
& =\frac{\alpha}{\alpha+\beta} \frac{1}{a_{0}+B\left(r, z_{f}\right)}\left(\frac{\mathrm{d} a_{0}}{\mathrm{~d} a}+\frac{\mathrm{d} z_{f}}{\mathrm{~d} a} \frac{\partial}{\partial z_{f}} B\left(r, z_{f}\right)\right)
\end{aligned}
$$

Plugging the equilibrium values of $z_{f}=t r_{f}$ and $P_{0}$ we get $\frac{\mathrm{d}}{\mathrm{d} a} \ln P(r)>0$ if and only if $R_{A}<t(1+a) \alpha /(\beta b)$, which is true at the equilibrium where $R_{A}<R_{A}^{* *}$.

\section{Appendix B: First-best}

In this Appendix, we first prove the existence of a global maximum for the planner's program. We then check the properties of this maximum. We finally derive the decentralized optimal policy.

\section{Global maximum}

In this section we prove that the first-best allocation is the unique solution of the interior solution of the first order condition of the planner's problem. The Cobb-Douglas utility function is given by $U(Z, H, P)=\kappa Z^{1-\alpha} H^{\alpha} P^{-\beta}$, where $1>\alpha, \beta>0$, and where $P(r)=1+a+b \int_{r}^{r_{f}} n(s) d s$. Then, using $n=1 / H$ and $U=\bar{u}$, we have $Z=\bar{v} n^{\frac{\alpha}{1-\alpha}} P^{\frac{\beta}{1-\alpha}}$, where $\bar{v} \equiv(\bar{u} / \kappa)^{\frac{1}{1-\alpha}}$. Using 
this we need to find the non-negative continuous function $n \in C\left(\left[0, r_{f}\right]\right)$ that maximizes $W(n) \equiv \int_{0}^{r_{f}}\left[Y-t r-Z(r)-R_{A} H(r)\right] / H(r) \mathrm{d} r$ or equivalently $W(n)=\int_{0}^{r_{f}}\left[(Y-t r) n(r)-\bar{v}(n(r))^{\frac{1}{1-\alpha}}\left(1+a+b \int_{r}^{r_{f}} n(s) \mathrm{d} s\right)^{\frac{\beta}{1-\alpha}}-R_{A}\right] \mathrm{d} r$

We prove that this function accepts a global maximum in four steps.

Step 1. Observe that $W(n)$ is a weakly sequentially continuous functional over the positive cone of $C\left(\left[0, r_{f}\right]\right)$. Weak sequential continuity means that, for any weakly converging sequence $\left\{n_{k}\right\}$ from $C\left(\left[0, r_{f}\right]\right)$ we have $W\left(n_{k}\right) \rightarrow$ $W\left(n_{0}\right)$, where $n_{0}$ is the weak limit of $\left\{n_{k}\right\}$. Weak convergence of $\left\{n_{k}\right\}$ to $n_{0}$ in $C\left(\left[0, r_{f}\right]\right)$ means that, for any Borel measure $\mu$ over $\left[0, r_{f}\right]$, we have

$$
\int_{0}^{r_{f}} n_{k}(r) \mathrm{d} \mu(r) \rightarrow \int_{0}^{r_{f}} n_{0}(r) \mathrm{d} \mu(r)
$$

Because $W(n)$ is a composition of integrals and continuous functions, it is clearly weakly continuous.

Step 2. Let us investigate the interior values for the first order condition. Maximizing pointwise $W(n)$ w.r.t $n(s)$ we get

$$
\begin{aligned}
\int_{0}^{r_{f}}\left[(Y-t r) n(r)-\bar{v}(n(r))^{\frac{1}{1-\alpha}}\left(1+a+b \int_{r}^{r_{f}} n(s) \mathrm{d} s\right)^{\frac{\beta}{1-\alpha}}-R_{A}\right] \mathrm{d} r \\
(Y-t s)+\frac{\bar{v}}{1-\alpha}(n(s))^{\frac{\alpha}{1-\alpha}}\left(1+a+b \int_{s}^{r_{f}} n(z) \mathrm{d} z\right)^{\frac{\beta}{1-\alpha}} \\
\quad-\frac{\bar{v} b \beta}{1-\alpha} \int_{0}^{r_{f}}(n(r))^{\frac{1}{1-\alpha}} I(s, r)\left(1+a+b \int_{r}^{r_{f}} n(z) \mathrm{d} z\right)^{\frac{\alpha+\beta-1}{1-\alpha}} \mathrm{d} r \\
=0
\end{aligned}
$$

where $I(s, r)$ is an indicator function equal to $(\mathrm{d} / \mathrm{d} n(s)) \int_{r}^{r_{f}} n(z) d z$, which yields 1 if $s \geq r$ and 0 otherwise. Therefore, after simplifying, using the 
definition of $P$ and swapping $r$ by $s$ for readability, we get

$$
(n(r))^{\frac{\alpha}{1-\alpha}}(P(r))^{\frac{\beta}{1-\alpha}}+b \beta \int_{0}^{r}(n(s))^{\frac{1}{1-\alpha}}(P(s))^{\frac{\alpha+\beta-1}{1-\alpha}} \mathrm{d} s=\frac{1}{\bar{v}}(1-\alpha)(Y-t r)
$$

When $r=0$, (5.1) boils down to the initial condition:

$$
(n(0))^{\frac{\alpha}{1-\alpha}}(P(0))^{\frac{\beta}{1-\alpha}}=\frac{1}{\bar{v}}(1-\alpha)
$$

Differentiating again w.r.t. $r$ and suppressing the argument $r$ yields

$$
\left(\frac{\alpha}{1-\alpha} \frac{\dot{n}}{n}+\frac{\beta}{1-\alpha} \frac{\dot{P}}{P}\right) n^{\frac{\alpha}{1-\alpha}} P^{\frac{\beta}{1-\alpha}}+b \beta n^{\frac{1}{1-\alpha}} P^{\frac{\alpha+\beta-1}{1-\alpha}}=-t \frac{1}{\bar{v}}(1-\alpha)
$$

Using $\dot{P}=-b n$, this simplifies to the system of two differential non-linear equations:

$$
\begin{aligned}
& \dot{n}=b \beta n^{2} P^{-1}-\frac{t}{\alpha \bar{v}}(1-\alpha)^{2} n^{\frac{1-2 \alpha}{1-\alpha}} P^{-\frac{\beta}{1-\alpha}} \\
& \dot{P}=-b n
\end{aligned}
$$

The solution is uniquely pinned down by the following two conditions:

$$
P\left(r_{f}\right)=1+a, \quad \text { and } \quad(n(0))^{\frac{\alpha}{1-\alpha}}(P(0))^{\frac{\beta}{1-\alpha}}=\frac{1}{\bar{v}}(1-\alpha) Y
$$

Lemma 1. Conditions (5.3), (5.4) and (5.5) accept a unique solution $n \in$ $C\left(\left[0, r_{f}\right]\right)$ such that $\kappa_{0}<n(r)$ with $\kappa_{0}>0$ close to zero.

Proof. The Picard-Lindelf theorem states the existence and uniqueness of first order differential equation with well-defined initial condition and uniformly Lipschitz continuous function. The RHS of (5.3) is uniform Lipschitz continuous in $n \in C\left(\left[0, r_{f}\right]\right)$ and $\kappa_{0}<n$. Suppose also that $P$ is continuous and not equal to zero in the RHS of (5.3). Then, by the Picard-Lindelf theorem, condition (5.3) accepts a unique solution $n$ that is continuous. By integrating (5.4) from $r_{f}$ where $P\left(r_{f}\right)=1+a$, we see that $P$ is also continuous and strictly above zero. This confirms our supposition that $P$ is continuous and not equal to zero in the RHS of (5.3). Then, both (5.3) and 
(5.4) accept a unique solution $n \in C\left(\left[0, r_{f}\right]\right)$ and $P \in C\left(\left[0, r_{f}\right]\right)$. QED

Step 3. Let us define the ball

$$
\mathcal{B}\left(\kappa_{0}, \kappa_{1}\right) \equiv\left\{n \in C\left(\left[0, r_{f}\right]\right): \kappa_{0} \leq n(r) \leq \kappa_{1} \forall r \in\left[0, r_{f}\right]\right\} .
$$

where $\kappa_{1}$ is an additional scalar. We have the following result:

Lemma 3. If $Y>t r_{f}$, there exist $\left(\kappa_{0}, \kappa_{1}\right)$ such that any non-negative global maximizer $n^{*} \in C\left(\left[0, r_{f}\right]\right)$ lies in the interior of $\mathcal{B}\left(\kappa_{0}, \kappa_{1}\right)\left(\kappa_{0}<n^{*}<\kappa_{1}\right)$ and is the global maximizer on $\mathcal{B}\left(\kappa_{0}, \kappa_{1}\right)$. The functions $n=\kappa_{1}$ and $n=\kappa_{0}$ are local minimizers on $\mathcal{B}\left(\kappa_{0}, \kappa_{1}\right)$.

Proof. Assume that, on the contrary, there is $A \subset\left[0, r_{f}\right]$ of positive Lebesgue measure, such that $n^{*}(r)=\kappa_{0}$ for all $r \in A$. Choose a small $\delta>0$ and $B \subset A$ such that the Lebesgue measure $B$ equals $\delta$, and consider $n_{\delta}$ such that $n_{\delta}(r)=\kappa_{0}$ for all $r \notin B$ and $\kappa_{0}<n_{\delta}(r)<\kappa_{0}+\delta$ for $r \in B$. By choosing $\delta$ sufficiently small, we can make $W\left(n_{\delta}\right)>W\left(\kappa_{0}\right)$, which contradicts $n^{*}$ being a maximizer. Indeed, let us write $W(n)=\int_{0}^{r f} w(r, n, P(n)) d r$ with $w(r, n, P)=(Y-t r) n-\bar{v} n^{\frac{1}{1-\alpha}} P^{\frac{\beta}{1-\alpha}}$ and $P(n)=1+a+b \int_{r}^{r_{f}} n(s) d s$. We have

$$
\begin{aligned}
w\left(r, n_{\delta}, P\right)-w\left(r, n^{*}, P\right) & =w_{n}^{\prime}\left(r, n^{*}, P^{*}\right)\left(n_{\delta}-n^{*}\right) \\
& +w_{P}^{\prime}\left(r, n^{*}, P^{*}\right)\left(P\left(n_{\delta}\right)-P\left(n^{*}\right)\right) \\
& +O\left(\delta^{2}\right)
\end{aligned}
$$

where

$$
\begin{aligned}
w_{n}^{\prime}(r, n, P) & =(Y-t r)-\frac{\bar{v}}{1-\alpha} n P^{\frac{\beta}{1-\alpha}} \\
w_{P}^{\prime}(r, n, P) & =-\frac{\beta \bar{v}}{1-\alpha} n^{\frac{1}{1-\alpha}} P^{\frac{\beta}{1-\alpha}-1} \\
P\left(n_{\delta}\right)-P\left(n^{*}\right) & \leq b \delta \max _{r \in B}\left[n_{\delta}(r)-n^{*}(r)\right]<b \delta^{2}
\end{aligned}
$$


Then, we compute

$$
\begin{aligned}
w\left(n_{\delta}\right)-w\left(\kappa_{0}\right)= & {\left[(Y-t r)-\frac{\bar{v}}{1-\alpha} \kappa_{0}\left(1+a+b \kappa_{0} r_{f}\right)^{\frac{\beta}{1-\alpha}}\right] \delta } \\
& -\bar{v} \frac{\beta}{1-\alpha}\left(\kappa_{0}\right)^{\frac{1}{1-\alpha}}\left(1+a+b \kappa_{0} r_{f}\right)^{\frac{\beta}{1-\alpha}-1} b \delta^{2}+O\left(\delta^{2}\right)
\end{aligned}
$$

where we used $P\left(\kappa_{0}\right)=1+a+b \kappa_{0} r_{f}$. Again, $W\left(n_{\delta}\right)>W\left(\kappa_{0}\right) \Longleftrightarrow$ $\int_{0}^{r_{f}} n_{\delta}(r) d r \geq \int_{0}^{r_{f}} \kappa_{0} d r$ for any sufficiently small $\delta$ if

$$
(Y-t r)>\frac{\bar{v}}{1-\alpha} \kappa_{0}\left(1+a+b r_{f} \kappa_{0}\right)^{\frac{\beta}{1-\alpha}}
$$

We just have to take a small enough $\kappa_{0}$ such that

$$
\frac{Y-t r_{f}}{\bar{v}}(1-\alpha) \geq \kappa_{0}\left(1+a+b \kappa_{0} r_{f}\right)^{\frac{\beta}{1-\alpha}}
$$

and we get the result $W\left(n_{\delta}\right)>W\left(\kappa_{0}\right)$. Finally, by this argument, we can state that $n(r)=\kappa_{0}$ is a (local) minimizer.

Assume now that there is $S \subset\left[0, r_{f}\right]$ of positive Lebesgue measure, such that $n^{*}(r)>\kappa_{1}$ for all $r \in S$, where

$$
\kappa_{1} \equiv \max _{n \geq 0}\left[Y n-\bar{v}(1+a) n^{\frac{1}{1-\alpha}}\right] .
$$

Then, consider $n^{* *}$, defined as

$$
n^{* *}(r) \equiv \begin{cases}\kappa_{1}, & r \in S, \\ n^{*}(r), & r \notin S .\end{cases}
$$

Then $W\left(n^{* *}\right)>W\left(n^{*}\right)$, which is a contradiction. Hence, $n^{*}(r) \leq \kappa_{1}$ for all $r \in\left[0, r_{f}\right]$. By the same argument, the solution $n^{* * *}(r) \equiv \kappa_{1}, r \in\left[0, r_{f}\right]$ is a (local) minimizer on the set of functions such that $0 \leq n(r) \leq \kappa_{1}$. QED

Step 4. We finish the proof by the following: Because $\mathcal{B}$ is a weakly compact subset of $C\left(\left[0, r_{f}\right]\right)$, while $W(n)$ is weakly sequentially continuous, there exists a global maximizer $n_{+}^{*}$ and global minimizer $n_{-}^{*}$ of $W(n)$ over $\mathcal{B}$ (see, e.g., Cea, "Optimization: Theory and Algorithms", 1978, Ch. 2). Since $n(r)=\kappa_{0}$ and $n(r)=\kappa_{1}$ define the border solutions on $\mathcal{B}\left(\kappa_{0}, \kappa_{1}\right)$, they are 
the only two border minimizers on $\mathcal{B}\left(\kappa_{0}, \kappa_{1}\right)$ : there exist no other local or global minimizers or maximizers on these borders. Hence, any maximizer is necessarily a solution in the interior of $\mathcal{B}\left(\kappa_{0}, \kappa_{1}\right)$. By Lemma 2, (5.3), (5.4) and (5.5) accept a unique solution with $\mathcal{B}\left(\kappa_{0}, \kappa_{1}\right)$, then this solution is the global maximizer.

Second order differential equations For $b \neq 0$, conditions (5.3) and (5.4) yield the following second-order non-linear differential equation in $P$ :

$$
\ddot{P}=-\beta \frac{(\dot{P})^{2}}{P}+\frac{b t(1-\alpha)^{2}}{\bar{v} \alpha} \frac{\left(-\frac{\dot{P}}{b}\right)^{\frac{1-2 \alpha}{1-\alpha}}}{P^{\frac{\beta}{1-\alpha}}}
$$

Using the solution of $P$, we can infer $n$ using $n=-\dot{P} / b$. Using $\bar{v}=(\bar{u} / \kappa)^{\frac{1}{1-\alpha}}$, the constant in the second term can be computed as $b t(1-\alpha)(\alpha \bar{u})^{\frac{-1}{1-\alpha}}$.

Shadow costs The first-best solutions with the shadow cost $\mu$ have been derived in the text. For consistency we recover $\mu$ from the above analysis. From (5.1), we can write

$$
(n(r))^{\frac{\alpha}{1-\alpha}}=\frac{1}{\bar{v}}(1-\alpha)(P(r))^{\frac{-\beta}{1-\alpha}}[Y-t r-b \mu(r)]
$$

where

$\mu(r) \equiv \frac{\beta \bar{v}}{(1-\alpha)} \int_{0}^{r}(n(s))^{\frac{1}{1-\alpha}}(P(s))^{\frac{\alpha+\beta-1}{1-\alpha}} \mathrm{d} s=\beta \bar{u}^{\frac{1}{1-\alpha}} \alpha^{\frac{\alpha}{1-\alpha}} \int_{0}^{r}(n(s))^{\frac{1}{1-\alpha}}(P(s))^{\frac{\alpha+\beta-1}{1-\alpha}} \mathrm{d} s$

is the co-state variable of the Hamiltonian. Simplifying, we get the density, land use and composite good consumptions

$$
\begin{aligned}
n(r) & =\alpha^{-1} \bar{u}^{-\frac{1}{\alpha}} P(r)^{-\frac{\beta}{\alpha}}[Y-t r-b \mu(r)]^{\frac{1-\alpha}{\alpha}} \\
H(r) & =\alpha \bar{u}^{\frac{1}{\alpha}} P(r)^{\frac{\beta}{\alpha}}[Y-t r-b \mu(r)]^{-\frac{1-\alpha}{\alpha}} \\
Z(r) & =\bar{v} n^{\frac{\alpha}{1-\alpha}} P^{\frac{\beta}{1-\alpha}}=(1-\alpha)[Y-t r-b \mu(r)]
\end{aligned}
$$

that are presented in the paper.

The system can then be represented by the tupple of functionals $(\mu, n, P)$ 
such that

$$
\begin{aligned}
\dot{P} & =-b n \\
\dot{\mu} & =\frac{\beta \bar{v}}{(1-\alpha)} n^{\frac{1}{1-\alpha}} P^{\frac{\alpha+\beta-1}{1-\alpha}} \\
n & =\alpha^{-1} \bar{u}^{-\frac{1}{\alpha}} P^{-\frac{\beta}{\alpha}}[Y-t r-b \mu]^{\frac{1-\alpha}{\alpha}}
\end{aligned}
$$

Substituting for the value of $n$, we can reduce this system to the system with the pair of functionals $(\mu, P)$

$$
\begin{aligned}
& \dot{P}=-\frac{b}{\alpha} \bar{u}^{-\frac{1}{\alpha}} P^{-\frac{\beta}{\alpha}}[Y-t r-b \mu]^{\frac{1-\alpha}{\alpha}} \\
& \dot{\mu}=\frac{\beta}{\alpha} \bar{u}^{-\frac{1}{\alpha}} P^{-\frac{\alpha+\beta}{\alpha}}[Y-t r-b \mu]^{\frac{1}{\alpha}}
\end{aligned}
$$

The initial conditions are $\mu(0)=0$ and $P\left(r_{f}\right)=1+a$. These initial conditions are easier to apply in numerical simulations.

\section{Negative land rent gradient}

Here, we express the second order condition at the fringe distance $r_{f}$. That is, $d \ln R / d r<0$ at $r=r_{f}$.

The land value described by the RHS of (4.7), say $R$, falls with $r$ if and only if

$$
\frac{\mathrm{d} \ln R}{\mathrm{~d} r}=-\frac{1}{\alpha} \frac{t+b \dot{\mu}}{Y-t r-b \mu}-\frac{\beta}{\alpha} \frac{\dot{P}}{P}<0
$$

at $r=r_{f}$. This is true if and only if

$$
(t+b \dot{\mu}) P>-\beta \dot{P}(Y-t r-b \mu)
$$

at $r=r_{f}$. We have $P\left(r_{f}\right)=(1+a), \dot{P}\left(r_{f}\right)=-b n\left(r_{f}\right)=-b \alpha^{-1} \bar{u}^{-\frac{1}{\alpha}}(1+a)^{-\frac{\beta}{\alpha}}$ $\left[Y-t r_{f}-b \mu\left(r_{f}\right)\right]^{\frac{1-\alpha}{\alpha}}, \dot{\mu}\left(r_{f}\right)=\frac{\beta}{\alpha} \bar{u}^{-\frac{1}{\alpha}}(1+a)^{-\frac{\alpha+\beta}{\alpha}}\left[Y-t r_{f}-b \mu\left(r_{f}\right)\right]^{\frac{1}{\alpha}}$. Replacing in the last expression, one can show that the inequality holds if $R_{A}<\frac{\alpha}{\beta} \frac{1+a}{b}\left(t+b \dot{\mu}\left(r_{f}\right)\right)$. 


\section{Decentralized optimal policy}

In the following, we discuss the decentralization of the first-best policy by a set of subsidies. First-best variables are denoted with the superscript ${ }^{o}$ as in the text while equilibrium variables carry no superscripts. Let the set of subsidies $\left(s_{Y}, s_{t}, s_{Z}, s_{H}\right)$ be such that the household's budget becomes $Y+s_{Y}=s_{Z} Z+s_{t} t r+s_{H} H R$. We get the following equilibrium variables:

$$
\begin{aligned}
H & =\frac{Y-s_{Y}-r t s_{t}}{\bar{u} \lambda s_{H}} \\
Z & =(1-\alpha) \frac{Y-s_{Y}-r t s_{t}}{s_{Z}} \\
\lambda & =\left(Y-s_{Y}-r t s_{t}\right)^{\frac{1}{\alpha}}\left(\frac{(1-\alpha)}{s_{Z}}\right)^{\frac{(1-\alpha)}{\alpha}} \frac{1}{s_{H}}(P)^{\frac{-\beta}{\alpha}} \bar{u}^{-1-\frac{1}{\alpha}}
\end{aligned}
$$

For decentralization, we impose that equilibrium consumptions are equal to those in the first-best: $H=H^{o}$ and $Z=Z^{o}$. So, we get the following identities:

$$
\begin{aligned}
\frac{Y-s_{Y}-r t s_{t}}{\bar{u} \lambda s_{H}} & =\frac{1}{\lambda^{o} \bar{u}}\left(Y-t r+\mu^{o}(r)\right) \\
(1-\alpha) \frac{Y-s_{Y}-r t s_{t}}{s_{Z}} & =(1-\alpha)\left(Y-t r+\mu^{o}(r)\right)
\end{aligned}
$$

where

$$
\lambda^{o}=(1-\alpha)^{\frac{(1-\alpha)}{\alpha}}\left(Y-t r+\mu^{o}(r)\right)^{\frac{1}{\alpha}} P^{o \frac{-\beta}{\alpha}} \bar{u}^{-\left(\frac{\alpha+1}{\alpha}\right)}
$$

With equal consumptions of land we also have equal pollution: $P=P^{o}$. We can simplify the two above identities as

$$
\frac{Y-s_{Y}-r t s_{t}}{Y-t r+\mu^{o}(r)}=s_{H}^{\alpha} s_{Z}^{(1-\alpha)}=s_{Z}
$$

This last expression gives four instruments $\left(s_{Y}, s_{t}, s_{Z}, s_{H}\right)$ and two equalities. We focus on a policy system that is independent of the parameter $\alpha$. This implies $s_{H}=s_{Z}=1$. So, the planner needs to verify the identity $s_{Y}+$ $r t\left(1-s_{t}\right)=\mu^{o}(r)$. The planner can set either a lump sum taxation such that $s_{t}=1$ and $s_{Y}=\mu^{o}(r)$, or a tax on travel such that $s_{Y}=0$ and $s_{t}=1-\mu^{o}(r) /(t r)$. The former tax is more attractive since it requires only proof of residence. The latter requires an additional (truthful) report of the 
traveled distances; also, it cannot be implemented by a fuel tax since $s_{t}$ is location dependent. 